\title{
Diversity of Carabid Beetles (Coleoptera: Carabidae) under Three Grassland Management Regimes in Northwestern China
}

\author{
Hui Wang ${ }^{1,2}$, Yuchen Zhao' ${ }^{1}$ and Xinpu Wang',* \\ ${ }^{1}$ School of Agriculture, Ningxia University, Yinchuan, 750021, China \\ ${ }^{2}$ Institute of Green Manure, Yan'an Academy of Agricultural Sciences, Yan'an, 716000, China
}

\begin{abstract}
A B S T R A C T
Enclosures, mowing, and sustainable grazing were used to help restore biodiversity and the production of the natural grasslands in China. The effects of grassland management on invertebrate diversity and its associated environmental factors were less reported in northern China. The relationship between the activity-density of carabid beetles and environmental factors was conducted under three different grassland management regimes (typical enclosure, enclosed mowing, and farmer grazing practice) in the Ningxia Hui Autonomous Region, northwestern China, from May to September 2017. Eighteen species from nine genera were collected in all regimes. The largest size of species and individuals occurred in mid-August, and species diversity and abundance were significantly greater in the typical enclosure area and the enclosed mowing area compared to the grazed area. The dominant species were Carabus vladimirskyi and Poecillus gebleri in enclosure areas and mowing areas while was Carabus glyptoterus in grazing areas. The key environmental factors associated with the activity-density of carabid beetles were soil organic matter, phosphorus, plant coverage, and plant density in enclosure areas and mowing areas. But soil temperature and $\mathrm{pH}$ were the main factors in grazing areas. This study implied that conservation of biodiversity requires consideration of different environmental condition in different grassland management regimes. Moreover, soil and vegetation restoration were more important for enhancing biodiversity in a grazed area than in enclosures and mowed areas in northwestern China.
\end{abstract}

Article Information
Received 08 June 2019
Revised13 August 2019
Accepted 14 September 2019
Available online 13 October 2021
Authors' Contribution
XPW and HW conceived the study
and designed the project. YCZ
helped in the experimental work.
HW analyzed the data and wrote the
manuscript.
Key words
Grassland management regimes,
Carabid beetles; Environmental
impacts; Activity-density

\section{INTRODUCTION}

$\mathrm{B}$ iodiversity and ecosystem service (BES) are an important issue in ecology (Mace et al., 2012; Kindsvater et al., 2018), and biodiversity and maintain a high level of multifunctionality in ecosystem service (Hector and Bagchi, 2007; Gamfeldt et al., 2008). Specifically, habitat environmental variables are critical factors affecting relationship between species diversity and habitat characteristics, specially such as vegetation and soil condition (Liu et al., 2016). However, because the patterns of land use and management regimes change or interaction (Frank et al., 2017), the connection between species diversity and habitat environmental variables becomes more complex, and the biodiversity also changes, especially in grassland ecosystems (Lyons et al., 2017).

Grazing, mowing, and enclosures (fencing) are important approaches used to protect grassland biodiversity (Tälle et al., 2015; Tälle et al., 2016). These approaches have often been used to manage grasslands in China rationally (Li et al., 2016; Qu et al., 2018). Grazing and mowing promotes grassland biodiversity by removing

\footnotetext{
* Corresponding author: wangxinpu@nxu.edu.cn 0030-9923/2021/0006-2389 \$9.00/0

Copyright 2021 Zoological Society of Pakistan
}

above-ground biomass and accelerating nutrient cycling (Al-Mufti et al., 1977). Moreover, enclosures can also deserve the species diversity and productivity of grasslands by eliminating the disturbances of trampling, animal feeding, and defecation (Yan et al., 2009; Li et al., 2014). However, most studies on grazing, mowing, and enclosures only were focused on plants. Different management regimes can affect the diversity of invertebrates by changing the original environmental conditions in some cases (Frank et al., 2017; Lyons et al., 2017). However, the mechanism of effects on animals are unclear, especially on the richness and diversity of invertebrates by management regimes (Jeanyves et al., 2009).

Ningxia Yunwu Mountain National Nature Reserve (NYMNNP) is an area of natural grassland restoration in the Loess Plateau of Western China. Its biodiversity has been substantially increased after more than 30 years of conservation (Zhao et al., 2014). Research on protected areas such as the NYMNNP have mainly focused on vegetation restoration and soil quality (Xie and Wittig, 2004; Cheng et al., 2012). Furthermore, studies on insect community structure and diversity have mainly focused on Orthoptera (Song et al., 2017), Lepidoptera (Zhang et al., 2016), and scarce Coleoptera (Wang et al., 2015). However, the research mentioned above largely ignored the effect of environmental factors on insect diversity which is one of 
crucial components in eco-service. And it is important to study the relationship between species diversity and the environment in different grassland management regimes during the process of large-scale habitat changes during the cycle of grassland recovery.

Carabid beetles (Coleoptera: Carabidae) were selected as representatives of the surface arthropods of grasslands for good indicators in our study. For example, carabid communities always respond in different ways to management regimes (Lyons et al., 2017; Lessard-Therrien et al., 2018). This study used carabid beetles as a model group to determine the effects of enclosure (excluding grazing livestock), mowing, and grazing on biodiversity in typical grasslands, as well as which environmental factors were driven the activity-density of carabid beetles in management regimes. A total of 13 environmental variables were considered including 6 vegetational characteristics (plant biomass, height, density, coverage, species richness, and aboveground litter), 7 soil factors (moisture, temperature, bulk density, organic matter, total phosphorus, total nitrogen, and $\mathrm{pH}$ value). The abundance of carabid responses to these factors were determined and the richness and diversity were assessed in three grassland management regimes (typical enclosure, enclosed mowing, and farmer grazing practice). The following hypotheses were tested:

Hypothesis 1: There will be relatively higher carabid species richness in grazed areas compared with enclosure and mowed areas. This is because grazing is an abiotic disturbance which increases landscape heterogeneity and biodiversity (Rook et al., 2004; Lyons et al., 2017).

Hypothesis 2: Plant biomass, density, coverage, height, and above ground litter will positively affect carabid activity-density because vegetation communities provide the microhabitats for carabid survival and vegetation serves as a shelter for the beetles (Fattorini et al., 2012; Wang et al., 2017).

\section{MATERIALS AND METHODS}

\section{Study areas and sampling design}

The study was conducted at the national nature reserve of the Yunwu Mountain grassland in Guyuan County, southern Ningxia, China $\left(36^{\circ} 13^{\prime}-36^{\circ} 19^{\prime} \mathrm{N}, 106^{\circ} 24^{\prime}-\right.$ $\left.106^{\circ} 28^{\prime} \mathrm{E}\right)($ Fig. 1A). This is a large grassland ecosystem dominated by Stipa bungeana (Gramineae) and located at an elevation of $1800 \sim 2150 \mathrm{~m}$. The climate is temperate arid and semi-arid with an annual mean temperature of $7^{\circ} \mathrm{C}$ and annual rainfall of $425.5 \mathrm{~mm}$. The annual amount of sunshine ranges from $2300 \sim 2500 \mathrm{~h}$ and the frostfree period is $137 \mathrm{~d}$. Soil types are evenly distributed between light black loessial soil and loessial soil. Three different grassland management regimes were selected as experimental areas in line with local conventional land management patterns. These were Typical Enclosure area (TE), Enclosed Mowed area (EM), and Farmer grazing Practice area (FP) (Fig. 1B). All of management had similar elevation and flat terrain.

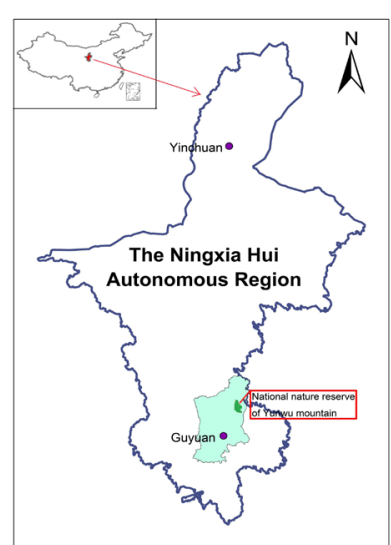

(A)

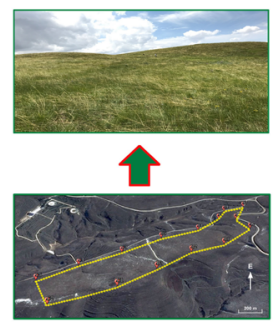

(C) TE

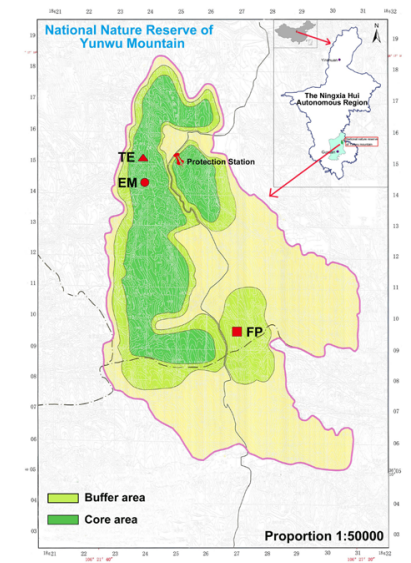

(B)

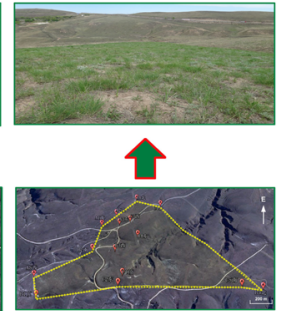

EM

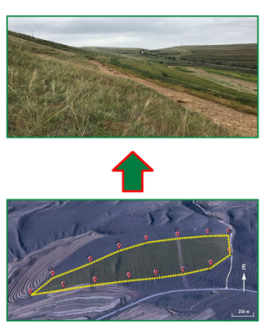

FP
Fig. 1. Study areas in southern Ningxia (A) where carabid beetles diversity was assessed (B) under three management regimes: TE, typical enclosure; EM, enclosed with mowing and FP, farmer grazing practice $(\mathrm{C})$

The typical enclosure area (TE), is situated about $1 \mathrm{~km}$ from the Yunwu Mountain protection station (Administrative department) on the western hillside. It has been enclosed for 30 years in the Core Area of the natural reserve. The main vegetation includes Stipa bungeana, Stipa grandis, Artemisia frigida, Thymus mongolicus, and Heteropappus altaicus. The average height of this plant community in summer is about $64 \mathrm{~cm}$, and the ground surface coverage is about $80 \%$.

The enclosed mowed area (EM) is located in the fire belt with different slope directions around the southern $2 \mathrm{~km}$ of the protection station. The grass vegetation is crossed by areas of mowed grasses that serve as fire belts. The grass is cut each May and mowing height exceeds 2/3 of grass height (almost all biomass including litter and dry matter was removed), as managed by the government. 
The main vegetation is similar to $\mathrm{TE}$, but the summer vegetation height is lower $(41 \mathrm{~cm})$ and ground coverage is reduced $(54 \%)$.

The farmer grazing practice area (FP) is situated on a hillside about $9.5 \mathrm{~km}$ southeast of the protection station in the Buffer Area of the natural reserve. This is a combination habitat of several farms and lightly grazed grassland (2 sheep per hectare, grazing 2-3 times a week). There is a sparse growth of Caragana korshinskii (Leguminosae), a shrub commonly used to improve soil quality and maintain soil moisture in northwest China. Major vegetation includes Stipa bungeana, Artemisia frigida, Thymus mongolicus, Potentilla acaulis. Potatoes and minor cereals are grown on the farms. The plant community average height is $39 \mathrm{~cm}$, and the coverage is $42 \%$. For management type, refer to Figure $1 \mathrm{C}$.

Table I. Correlation of eigenvalues for PCA axis and environment variables.

\begin{tabular}{lllll}
\hline Items & AX1 & AX2 & AX3 & AX4 \\
\hline Eigenvalues & 0.566 & 0.090 & 0.081 & 0.053 \\
Species-environment correlations & 0.951 & 0.863 & 0.572 & 0.527 \\
Cumulative percentage & 56.6 & 65.6 & 73.7 & 79.1 \\
\hline
\end{tabular}

\section{Carabid sampling}

Carabid beetles were monitored at 45 sample sites ( 15 sites per management type) using pitfall traps (Schirmel et al., 2015; Lyons et al., 2017). Each sampling site area was $50 \mathrm{~m}^{2}$ and separated from other sampling sites by at least $150 \mathrm{~m}$. At each sampling site, five pitfall traps were placed at a distance of least $5 \mathrm{~m}$ from each other. Pitfall traps were made of plastic cups (diameter: $7.15 \mathrm{~cm}$, depth: $9 \mathrm{~cm}$ ) sunk into the ground and filled with $60 \mathrm{~mL}$ of an attractant solution (vinegar, sugar, $70 \%$ ethanol and water in a 2:1:1:20 ratio (wt/wt). Pitfall traps were set once monthly, at mid-month, from May to September in 2017, and collected three days later.

A total of 1,125 pitfall traps were used in our study (45 sampling sites $\times 5$ pitfall traps $\times 5$ sampling dates). For analysis, the data from the 5 pitfall traps of each sampling site were pooled as a single sampling unit because the soil and vegetation characteristics were measured at the sampling site level for each of the 45 sites. Carabid data were obtained from all of the sampling sites, including those with no beetles; the annual number of lost traps was less than 10 . The trapped beetles were counted, identified by taxonomist experts from the Chinese Academy of Sciences, and preserved in the insect collection of the school of agriculture, Ningxia University.
Vegetation and soil sampling

Thirteen environmental variables were measured, including six vegetation and seven soil factors (Table II). Except for soil organic matter, total nitrogen, total phosphorus, and $\mathrm{pH}$, which were measured only once in August of 2017; other variables were measured each month. All of the environmental variables were investigated at the same time on the same day by three groups of survey teams under different management regimes.

In each sampling site, one quadrat frame of $0.25 \mathrm{~m}^{2}$ was set up to record plant dry biomass $\left(\mathrm{PB}, \mathrm{g} / \mathrm{m}^{2}\right)$, cover (PC, \% of soil covered by plants), density (PD, number of plants per $\mathrm{m}^{2}$ ), height $(\mathrm{PH}$, average, $\mathrm{cm})$, richness (PSD, plant species diversity), and aboveground litter (litter, dry mass, $\mathrm{g} / \mathrm{m}^{2}$ ) (Tsafack et al., 2019).

One sample near the quadrat frames was collected to measure soil moisture (SM, $10 \mathrm{~cm}$ depth, Thermogravimetric method, \%) (Majumdar, 2001), bulk density $\left(\mathrm{SBD}\right.$, Ring knife method, $\left.\mathrm{g} / \mathrm{cm}^{3}\right)$, total nitrogen $(\mathrm{N}$, Kjeldahl nitrogen, $\mathrm{g} / \mathrm{kg}$ ), total phosphorus ( $\mathrm{P}, \mathrm{Mo}-\mathrm{Sb}$ colorimetric method, $\mathrm{g} / \mathrm{kg}$ ), soil organic matter $(\mathrm{C}$, Potassium dichromate volume method, $\mathrm{g} / \mathrm{kg}$ ), and soil $\mathrm{pH}$ value $(\mathrm{pH})$ was determined using a $\mathrm{pH}$ acid-base indicator. This method of soil variables specific reference to protocol of the Chinese Academy of Sciences, Nanjing Institute of Soil Science Editor Soil Physical and Chemical Analysis in 1978 .

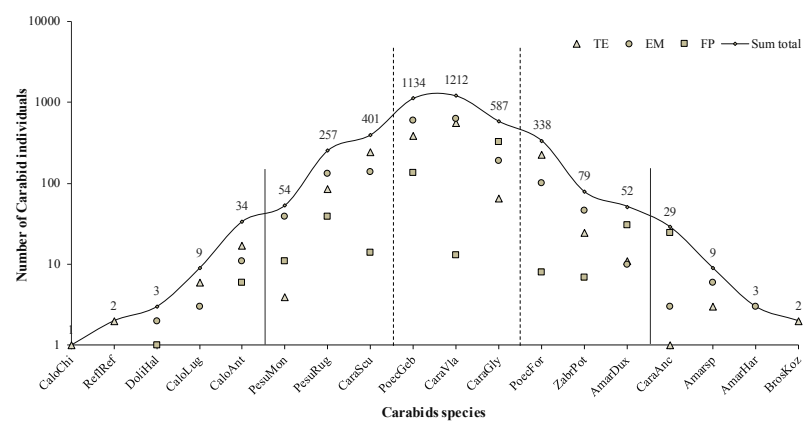

Fig. 2. Carabidae species and individuals in the natural grassland of Yunwu Mountain. Vertical axes were logtransformed; CaloChi, Calosoma chinense; ReflRef, Reflexisphodrus reflexipennis; DoliHal, Dolichus halensis; CaloLug, Calosoma lugens; CaloAnt, Calosoma anthrax; PesuMon, Pseudotaphoxenus mongolicus; PesuRug, Pseudotaphoxenus rugipennis; CaraScu, Carabus sculptipennis; PoecGeb, Poecillus gebleri; CaraVla, Carabus vladimirskyi; CaraGly, Carabus glyptoterus; PoecFor, Poecillus fortipes; ZabrPot, Zabrus potanini; AmarDux, Amara dux; CaraAnc, Carabus anchocephalus; Amarsp, Amara sp; AmarHar, Amara harpaloides; BrosKoz, Broscus kozlovi. 
Table II. Correlation coefficients of environmental variables and the first two PCA axes.

\begin{tabular}{|c|c|c|c|c|c|c|c|c|c|c|c|c|c|}
\hline \multirow[t]{2}{*}{ Variables } & \multicolumn{7}{|c|}{ Soil } & \multicolumn{6}{|c|}{ Vegetation } \\
\hline & SM & SBD & Temp & $\mathrm{C}$ & $\mathbf{P}$ & $\mathbf{N}$ & pH & PB & $\mathbf{P H}$ & PD & PC & PSD & Litter \\
\hline $\mathrm{AX} 1$ & -0.5603 & 0.4374 & 0.3139 & -0.9179 & -0.7638 & -0.4397 & 0.6407 & -0.1887 & -0.5344 & -0.6191 & -0.7135 & 0.1549 & -0.5064 \\
\hline $\mathrm{AX} 2$ & -0.4510 & -0.4103 & 0.5981 & 0.0565 & 0.0327 & -0.3067 & 0.2620 & -0.6378 & -0.4588 & 0.4307 & -0.4018 & 0.3293 & -0.4910 \\
\hline
\end{tabular}

SM, Soil moisture; SBD, Soil bulk density; Temp, Soil temperature; C, Soil organic matter; P, Total phosphorus; N, Total nitrogen; pH, pH value; PB, Plant biomass; PH, Plant height; PD, Plant density; PC, Plant coverage; PSD, Plant species diversity; Litter, Aboveground litter.

\section{Data analysis}

The activity density of the species was calculated as the number of beetles in the sampling site area. The dominant species (more than 10\%), common species (1-10\%) and scarce species (less than 1\%) were divided according to the proportion of the number of individuals. We used the Shannon-Wiener index $\left(H^{\prime}\right)$ to calculate the species diversity of carabids, $H^{`}=\sum^{s}{ }_{i=1} P i \ln P i$; Species richness (D) was determined by Margalef richness index, $D=(S$ $1) / \ln N$; Pielou evenness index $\left(J^{\prime}\right)$ was used to evaluate community stability, $J^{\prime}=\mathrm{H}^{\prime} / \ln S$; Simpson dominance index (C) was used to assess the of concentration community dominance, $C=\sum_{i=1}^{s} P i^{2}$. In the above formula, the $S$ is the number of species in the community, $N$ is the total number of collected individuals, $P i$ is the proportion of the number of the $i$ group individuals in the total number of individuals in the community (Ma, 1994; Spellerberg and Fedor, 2003).

Differences in species richness and diversity among the three management regimes were tested using oneway Analysis of Variance (one-way ANOVA) followed by post-hoc Tukey tests. Statistical analysis was done with SAS 8.2. Graph Pad Prism 5.0 was used for figure preparation. The relationships between carabid activitydensity and the environmental variables were analyzed using Detrended Correspondence Analysis (DCA) and Principal Components Analysis (PCA) with Canoco 4.5 software (Lai, 2013). All data were standardized by [log $(\mathrm{x}+1)]$.

\section{RESULTS}

Carabid beetle species composition among the three management regimes

A total of 4206 carabid beetles were collected, belonging to 18 species and 9 genera (Fig. 2). There are fewer dominant species and more scarce species in our study in 2017, but the distribution of dominant and scarce species exhibited clear differences in each management type. Carabus vladimirskyi was dominant in TE and EM, accounting for $33.98 \%$ and $32.92 \%$ respectively, while it was a scarce species in PE, accounting for only $2.11 \%$.
Poecillus gebleri was a dominant species in the three regimes, accounting for $23.73 \%, 31.32 \%$, and $21.88 \%$ of the total respectively. Carabus glyptoterus was dominant in FP, accounting for $53.00 \%$, but only $4 \%$ and $9.99 \%$ in TE and EM, respectively. The scarce species Calosoma lugens and scarce genus Amara sp were only found in TE and EM.

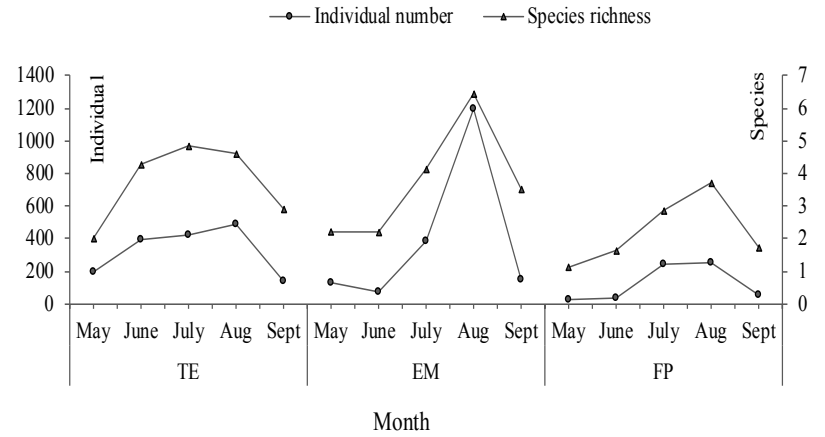

Fig. 3. Temporal dynamics of carabid beetle individual and species richness in different management regimes.

Carabid beetles spatiotemporal dynamic and diversity analysis

The abundance of individuals and species richness were relatively similar in three management regimes. With the exception of species richness in TE, the peaks of species and individuals in other management regimes occurred in mid-August and sub-peaks appeared in mid-July (Fig. 3). The fluctuation of carabid numbers in EM may be related to the primary productivity increase after artificial mowing in May. There was no significant difference between richness $(\mathrm{F}=13.61, P<0.001)$ and activity density $(\mathrm{F}=23.1$, $P<0.001)$ in EM and TE, but they were both significantly higher than FP (Fig. 4). The Shannon-Wiener diversity index of TE and EM was significantly higher than FP $(\mathrm{F}=6.85, P=0.003)$, the Simpson dominance index was significantly lower than FP $(\mathrm{F}=7.33, P=0.002)$. There was no significant difference between TE and EM. Moreover, there was no significant difference in Pielou evenness index and Margalef richness index among the three management 
regimes (Fig. 5). These results suggest that the activitydensity as well as the richness and diversity of carabids are affected by grassland management regimes. In addition, the results of boxplot distribution of four diversity indices showed that the dispersion degree of FP was higher than the other areas. There have higher species diversity, less variation and stronger community stability in TE and EM habitats.

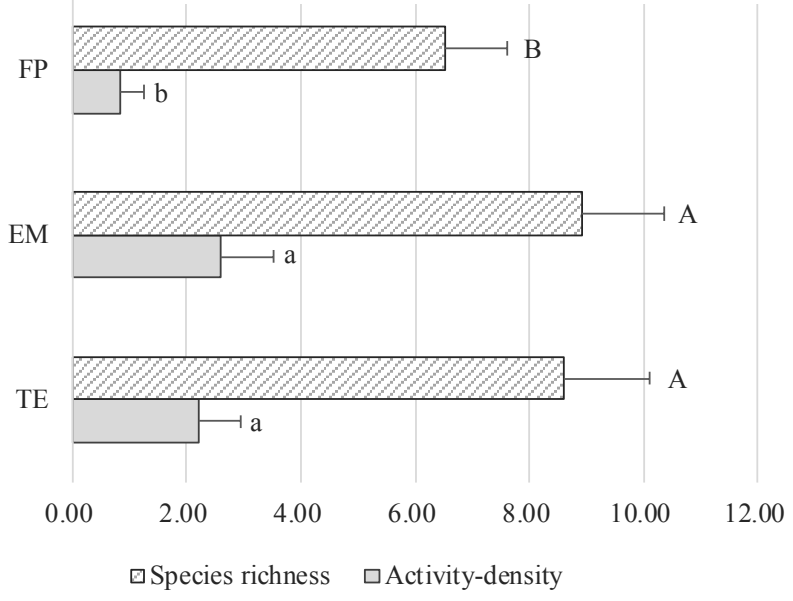

Fig. 4. Spatial dynamics of carabid beetle activity density and species richness in different management regimes; ANOVA was used to compare differences among different interference levels. Different letters on the same type of bar indicate significant differences at the $P<0.05$ level.
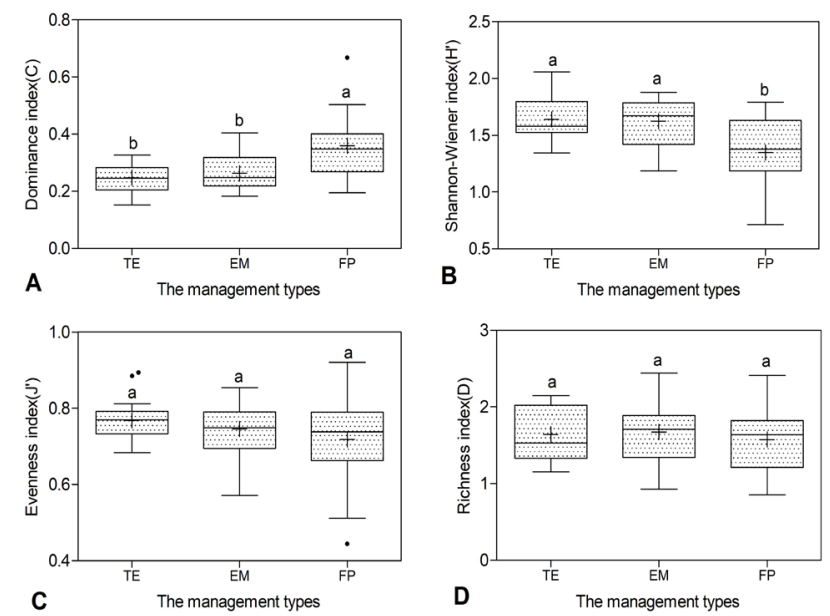

Fig. 5. Boxplot of (A) Dominance index, (B) ShannonWiener index, (C) Evenness index, (D) Richness index; The differences of carabid community diversity indices among different types of interference were compared using the one-way ANOVA. Different letters above the boxes indicate significantly different means according to the Tukey test $(P<0.05)$.
The main environmental factors affecting carabids activity density

The distribution characteristics of carabid communities were significantly affected by environmental factors, since the correlations between species distribution for the first two axes and environmental variables reached 0.951 and 0.863 in PCA analysis (Table I). C, P, PC, PD, and $\mathrm{pH}$ had close correlations with the first principal component axis, with correlation coefficients of -0.9179 , $-0.7639,-0.7135,-0.6191$, and 0.6407 , respectively. PB and Temp had close correlations with the second axis, with correlation coefficients of -0.6378 and 0.5981 (Table II). Therefore, the main environmental factors that affected the activity-density of the carabid were C, P, PC, PD, pH, PB, and Temp.

The relationship between each species and environmental variable is presented in Figure 6A. Five environmental variables showed significant effects Axis 1: $\mathrm{C}, \mathrm{P}, \mathrm{PD}$, and $\mathrm{PC}$ had negative correlations and $\mathrm{pH}$ had a positive correlation. Among these, there were four abundant species (CaraVla, CaraScu, PoecFor, PoecGeb) with high abundance levels that were positively correlated with C, P, PD, and PC. Two abundant species (CaraGly, CaraAnc) were positively correlated with $\mathrm{pH}$. Two environmental variables showed significant effects: Axis 2: PB (negative) and Temp (positive). Among these, only one dominant species (CaraGly) was positively correlated with Temp. There were only two scarce species (CaloChi, BrosKoz) positively correlated with PB. PB was a limiting factor for dominant species (Fig. 6A).
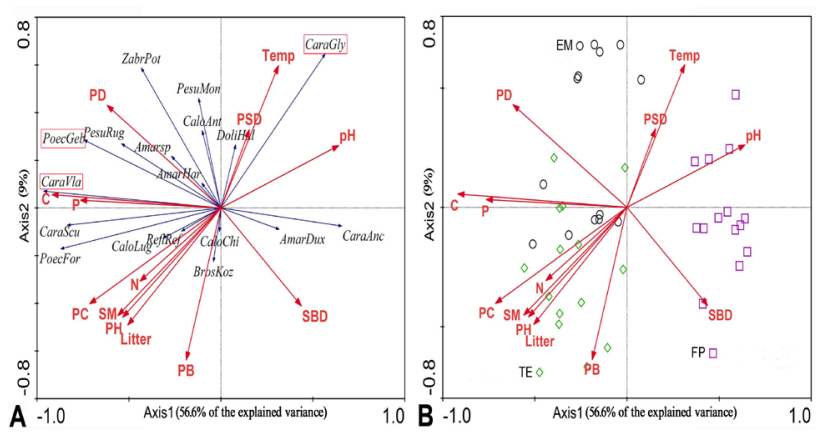

Fig. 6. PCA ordination of (A) 18 species of beetle and 13 environmental factors, (B) 45 sample sites and 13 environmental factors; PB, Plant biomass; PC, Plant coverage; PD, Plant density; PH, Plant height; PSD, Plant species diversity; Litter, Aboveground litter; SBD, Bulk density; SM, Soil moisture; Temp, Soil temperature; C, Soil organic matter; $\mathrm{P}$, Total phosphorus; N, Total nitrogen; $\mathrm{pH}, \mathrm{pH}$ value. Environmental factors are represented by red arrows, carabid species are represented by blue arrows, dominant species are enclosed in red rectangular boxes. 
Table III. Correlation coefficients between the 13 environmental variables.

\begin{tabular}{|c|c|c|c|c|c|c|c|c|c|c|c|c|c|}
\hline Relevance & SM & SBD & Temp & Litter & $\mathrm{C}$ & $\mathbf{P}$ & $\mathbf{N}$ & pH & PB & $\mathbf{P H}$ & PD & PC & PSD \\
\hline SM & 1 & & & & & & & & & & & & \\
\hline SBD & 0.1318 & 1 & & & & & & & & & & & \\
\hline Temp & -0.5214 & -0.2323 & 1 & & & & & & & & & & \\
\hline Litter & 0.7014 & 0.2148 & -0.546 & 1 & & & & & & & & & \\
\hline $\mathrm{C}$ & 0.5291 & -0.5676 & -0.1997 & 0.4698 & 1 & & & & & & & & \\
\hline $\mathrm{P}$ & 0.5127 & -0.197 & -0.2444 & 0.3649 & 0.7093 & 1 & & & & & & & \\
\hline $\mathrm{N}$ & 0.4999 & 0.0048 & -0.1786 & 0.7278 & 0.4785 & 0.4019 & 1 & & & & & & \\
\hline $\mathrm{pH}$ & -0.5951 & 0.1982 & 0.4187 & -0.6999 & -0.6993 & -0.5100 & -0.6426 & 1 & & & & & \\
\hline PB & 0.4736 & 0.3545 & -0.4021 & 0.7559 & 0.1187 & 0.1098 & 0.5642 & -0.5022 & 1 & & & & \\
\hline $\mathrm{PH}$ & 0.6855 & 0.2647 & -0.4767 & 0.8100 & 0.5072 & 0.4731 & 0.5505 & -0.6492 & 0.7019 & 1 & & & \\
\hline PD & 0.1241 & -0.6788 & 0.0321 & -0.1444 & 0.6816 & 0.4938 & -0.1652 & -0.2986 & -0.4365 & 0.0415 & 1 & & \\
\hline $\mathrm{PC}$ & 0.6913 & -0.0904 & -0.5419 & 0.8615 & 0.7125 & 0.5517 & 0.7247 & -0.8094 & 0.6580 & 0.7960 & 0.1592 & 1 & \\
\hline PSD & -0.5066 & -0.3211 & 0.3180 & -0.6672 & -0.1524 & -0.1864 & -0.4104 & 0.377 & -0.5196 & -0.528 & 0.2987 & -0.4763 & 1 \\
\hline
\end{tabular}

The correlation coefficient showed significant difference at $P<0.05$ level in Monte Carlo permutation test.

The relationship between sampling sites and environmental factors in different management regimes was analyzed (Fig. 6B). Most of the TE sites were distributed in the third quadrant, showing a strong correlation with PC, N, SM, PH, Litter, and PB. More EM sites were distributed in the second quadrant, showing a strong correlation with PD, C, and P. Some sample sites between the two management regimes had interaction effects which were affected by the same environmental factors. The FP sites were distributed in the first and fourth quadrant and were positively correlated with Temp, $\mathrm{pH}, \mathrm{SBD}$, and PSD.

Activity-density and richness of carabids in FP was the lowest, and temp and $\mathrm{pH}$ were the most important factors in FP. C, P, PC, PD and PB positively affect carabid activity-density in TE and EM.

\section{The correlation between environmental factors}

The vegetation-soil interactions explained more of the composition variation in the beetle community. The main environmental factors that affected the activity-density of the carabid were $\mathrm{C}, \mathrm{P}, \mathrm{PC}, \mathrm{PD}, \mathrm{pH}$, $\mathrm{PB}$, and Temp (Table II). These main factors were affected by secondary factors. The correlation between environmental factors showed that litter, $\mathrm{C}, \mathrm{N}, \mathrm{PH}$ had a strong positive correlation and $\mathrm{pH}$ had a strong negative with $\mathrm{PC} ; \mathrm{N}, \mathrm{PB}, \mathrm{PH}, \mathrm{SM}$ had a strong positive correlation with Litter; There is a strong positive correlation between PH and PB, C and P (Table III).

\section{DISCUSSION}

Enclosure (TE), mowing (EM), and grazing (FP) are important land management regimes for biodiversity conservation in grassland ecosystems (Li et al., 2016; Tälle et al., 2016). The community structure of carabids was significantly different among these three management regimes and this was influenced by environmental variables in our study.

Activity-density and richness of carabids in FP was the lowest among the three grassland management (Figs. 4 and 5), which did not support our Hypothesis 1 and contrary to result of Rook and Scimone (Rook et al., 2004; Scimone et al., 2007). Although grazing can increase habitat heterogeneity and biodiversity, most studies have only focused on vegetation communities (Scimone et al., 2007) and the carabid response to grazing system appears different than the vegetation response (Lyons et al., 2017). In addition, it is recognized that overgrazing leads to grassland degradation, and long-term grazing will increase soil bulk density and decrease moisture, affecting the growth and survival of eggs and immatures (Supplementary Table I) (Lövei and Sunderland, 1996; Magura et al., 2003). This appears to be the reason why carabid density is lower in FP areas with long term management. Therefore, it is not consistent for the carabid diversity with habitat heterogeneity after grazing in smaller scale.

The richness, activity-density, and diversity of carabids in the TE and EM were significantly higher, which also did not support our Hypothesis 1. EM was higher than TM but not significant. These results 
suggest that enclosure and mowing can enhance carabid community diversity. As the main measure for grassland restoration, enclosure will promote vegetation succession to a climax community with corresponding changes of physical and chemical properties of the soil (Yan et al., 2009). During this process, enclosure may provide a favorable environment for carabid survival. Liu et al. (2012) confirmed that the abundance and diversity of ground arthropods respond positively to enclosure areas. Mowing provides a better predation situation for carabids by reducing vegetation coverage, density, height, and biomass in our study (Supplementary Table II). Sparse vegetation areas are ideal hunting areas for mobile grounddwelling soil arthropods such as carabids (Kromp, 1999; Batáry et al., 2012). In addition, Birkhofer et al. (2015) found that frequent mowing led to a higher abundance of predaceous and omnivorous ground beetles but a lower abundance of herbivorous species. However, since most of the dominant and abundant species are predatory, as indicated by feeding and literature references in our study, carabid activity-density and diversity were higher in the EM. This proved that EM had a strong influence on the distribution of carabids. Although EM sample as fire belt has a small area, it has a wide range. The above results were also supported that appropriate grassland management regimes such as enclosure and mowing can beneficially affect carabid species composition (Lyons et al., 2017) and biodiversity benefits of grasslands (Tälle et al., 2016).

In our study, the results showed that plant coverage, density, biomass will affect activity-density in TE and EM positively, which supports our Hypothesis 2. This indicates that vegetation provide the microhabitats needed for carabid survival as shelter (Wang et al., 2017). In addition, soil organic matter, total phosphorus was affected the activity-density of carabids in the TE and EM areas significantly. Other studies were supported our finding, for instance, Liu et al. (2010) demonstrated that soil arthropod abundance, including some Coleoptera larvae, is related to soil organic matter. Total phosphorus is associated with dung beetles and saprophytic beetles (Liu, 2011). Soil temperature and $\mathrm{pH}$ value were the main factors in FP. We thought soil temperature should have a slight impact on beetle density because it needs a larger scale, but the results showed that soil temperature was a key factor. Therefore, the main reason is that grazing increases soil bulk density. And then, high-density soil leads to lower soil moisture, which in turn leads to an increase in soil temperature. Secondly, we also speculate that it may be vegetation effects (grazing reduces PC, PD), but not regional issues (9.5 km apart) and the slope (flat terrain). We thought that $\mathrm{pH}$ value had a greater impact on carabids in FP due to specialized land management. (Vittum and Tashiro, 1980) showed that larvae of the Japanese beetle do not survive in acidic environments $(\mathrm{pH}<5.9)$. We support this finding because grazing leads to a decrease in plant biomass and an increase in soil salinity, which in turn leads to an increase in $\mathrm{pH}$, especially in Northwest China, where precipitation is scarce (Li et al., 2006).

Moreover, the vegetation-soil interactions explained more of the variation in the beetle community than vegetation or soil alone (Liu et al., 2016). Exactly as result that soil organic matter, total phosphorus affects carabids by driving the growth and reproduction of vegetation. Liu et al. (2016) showed that the herbaceous plant biomass had a significant negative direct effect on species richness, but indirectly affected species richness via positive effects on shrub height and soil $\mathrm{pH}$. In addition, the secondary factors also interact with each other, such as total nitrogen, plant biomass, plant height, soil moisture had a strong positive correlation with litter. We also supported the changes to vegetation variables had stronger bottom-up effects on beetle species composition than altered soil (Scherber et al., 2010; Gossner et al., 2019), because plant coverage as a main factor was affected by other soil variables in our study. Moreover, predator-prey interaction should be considered. Carabid beetles are active predators, and should be strongly influenced by the abundance of their prey group (Symondson et al., 2006). Therefore, carabids should be indirectly affected by vegetation and soil, or directly affected through by prey.

In conclusion, this study determined the effects of the management regimes of enclosure, mowing, and grazing on the diversity of carabid beetles. The main environmental factors are associated with the activitydensity of the carabids. The conservation of biodiversity requires consideration of different environmental variables in different grassland management regimes. Specifically, restoration on soil quality and vegetations are relatively more important to sustain the biodiversity of grazed areas. Further research should clarify the biology and ecological service of key carabid species and explore the relationships between environmental factors and taxonomic and functional group of carabid beetles.

\section{ACKNOWLEDGMENTS}

We thank Dr. Hongbin Liang (Institute of Zoology, Chinese Academy of Sciences, Beijing, China) for assistance in carabid identification. We thank Dr. Myron Zalucki and Dr. Lynda Perkins (School of Biological Sciences, University of Queensland, Brisbane, Australia) for helpful discussion and linguistic assistance during manuscript preparation. Wenjun Li (Management Department of Yunwu Mountain National Nature Reserve) 
provided a map of Yunwu Mountain National Nature Reserve. Finally, we thank LetPub (www.letpub.com) for linguistic assistance during manuscript preparation.

This research was financially supported by the National Natural Science Foundation of China (No. 31660630) and the First-class disciplines of Prataculture Science from Ningxia University (Grant No. NXYLXK2017A01).

\section{Supplementary material}

There is supplementary material associated with this article. Access the material online at: https://dx.doi. org/10.17582/journal.pjz/20190608100630

\section{Statement of conflict of interest}

The authors declare no conflict of interest.

\section{REFERENCE}

Al-Mufti, M.M., Sydes, C.L., Furness, S.B., Grime, J.P. and Band, S.R., 1977. A quantitative analysis of shoot phenology and dominance in herbaceous vegetation. J. Ecol., 65: 759-791. https://doi. org $/ 10.2307 / 2259378$

Batáry, P., Holzschuh, A., Orci, K.M., Samu, F. and Tscharntke, T., 2012. Responses of plant, insect and spider biodiversity to local and landscape scale management intensity in cereal crops and grasslands. Agric. Ecosyst. Environ., 146: 130-136. https://doi. org/10.1016/j.agee.2011.10.018

Birkhofer, K., Diekötter, T., Meub, C., Stötzel, K. and Wolters, V., 2015. Optimizing arthropod predator conservation in permanent grasslands by considering diversity components beyond species richness. Agric. Ecosyst. Environ., 211: 65-72. https://doi. org/10.1016/j.agee.2015.05.014

Cheng, J., Hu, J.C.T., Shao, H. and Zhang, J., 2012. Dynamic changes of Stipa bungeana steppe species diversity as better indicators for soil quality and sustainable utilization mode in Yunwu Mountain Nature Reserve, Ningxia, China. Acta Hydrobiol. Sin., 40: 127-133. https://doi.org/10.1002/ clen. 201000438

Colombini, I., Chelazzi, L. and Scapini, F., 1994. Solar and landscape cues as orientation mechanisms in the beach-dwelling beetle, Eurynebria complanata (Coleoptera, Carabidae). Mar. Biol., 118: 425-432.

Fattorini, S., Santoro, R., Maurizi, E., Acosta, A.T.R. and Di Giulio, A., 2012. Environmental tuning of an insect ensemble: The tenebrionid beetles inhabiting a Mediterranean coastal dune zonation. CR. Biol., 335: 708-711. https://doi.org/10.1016/j.crvi.2012.09.009

Frank, K., Hülsmann, M., Assmann, T., Schmitt, T. and
Blüthgen, N., 2017. Land use affects dung beetle communities and their ecosystem service in forests and grasslands. Agric. Ecosyst. Environ., 243: 114122.

Gamfeldt, L., Hillebrand, H. and Jonsson, P., 2008. Multiple functions increase the importance of biodiversity for overall ecosystem functioning. Ecology, 89: 1223-1231. https://doi.org/10.1890/062091.1

Gossner, M.M., Falck, K. and Weisser, W.W., 2019. Effects of management on ambrosia beetles and their antagonists in European beech forests. Forest Ecol. Manage., 437: 126-133. https://doi.org/10.1016/j. foreco.2019.01.034

Hector, A. and Bagchi, R., 2007. Biodiversity and ecosystem multifunctionality. Nature, 448: 188. https://doi.org/10.1038/nature05947

Jeanyves, H., Jaboury, G. and Thomas, W., 2009. Meadow harvesting techniques and their impacts on field fauna. Agric. Ecosyst. Environ., 130: 1-8. https://doi.org/10.1016/j.agee.2008.11.014

Kindsvater, H.K., Dulvy, N.K., Horswill, C., Juan Jordá, M.J., Mangel, M. and Matthiopoulos, J., 2018. Overcoming the data crisis in biodiversity conservation. Trends Ecol. Evol., 33: 676-688.

Kromp, B., 1999. Carabid beetles in sustainable agriculture: a review on pest control efficacy, cultivation impacts and enhancement. Agric. Ecosyst. Environ., 74: 187-228. https://doi.org/10.1016/ B978-0-444-50019-9.50014-5

Lai, J., 2013. Canoco 5: a new version of an ecological multivariate data ordination program. Biodiv. Sci., 21: 765-768. https://doi.org/10.3724/ SP.J.1003.2013.04133

Lessard-Therrien, M., Humbert, J.Y., Hajdamowicz, I., Stańska, M., Klink, R.V., Lischer, L. and Arlettaz, R., 2018. Impacts of management intensification on ground-dwelling beetles and spiders in semi-natural mountain grasslands. Agric. Ecosyst. Environ., 251: 59-66.

Li, C.S., Yang, X.H., Chun Tang, Y., Jun, C.L., Hong Yan, L., Wang, Z. and Bai, F., 2006. Effects of grazing on spatial heterogeneity of soil moisture and salt content in saline grassland in low terrace of the Yellow River. Acta Ecol. Sin., 26: 2402-2408.

Li, J.P., Zheng, Z.R., Zhao, N.X. and Gao, Y.B., 2016. Relationship between ecosystem multifuntionality and species diversity in grassland ecosystems under land-use types of clipping, enclosure and grazing. Chin. J. Pl. Ecol., 40: 735-747. https://doi. org/10.17521/cjpe.2015.0457

Li, X., Gao, Q. and Wang, Y., 2014. Species richness 
within a six-year slope exclosure in a temperate grassland and its relationship with above ground biomass. Ecol. Environ., 23: 398-405.

Li, X., Liu, Y., Duan, M., Yu, Z. and Axmacher, J.C., 2018. Different response patterns of epigaeic spiders and carabid beetles to varying environmental conditions in fields and semi-natural habitats of an intensively cultivated agricultural landscape. Agric. Ecosyst. Environ., 264: 54-62. https://doi.org/10.1016/j. agee.2018.05.005

Liu, J.L., Li, F.R., Sun, T.S., Ma, L.F., Liu, L.L. and Yang, K., 2016. Interactive effects of vegetation and soil determine the composition and diversity of carabid and tenebrionid functional groups in an arid ecosystem. J. Arid Environ., 128: 80-90.

Liu, R.T., Xue Bin, L., Xin, M., Lin, M.A. and Liu, K., 2012. Response of the ground arthropod community to exclosure of desert steppe in semi-arid regions. Acta Pratacult. Sin., 21: 66-74.

Liu, X.M., 2011. Influence of grazing activity on dung beetle assemblages in a typical steppe in Inner Mongolia. Acta entomol. Sin., 54: 1406-1415.

Liu, Z.X., Yu, D., Ou, Zhi, Y., Su, K. Zhen, Li, and Tong, F.C., 2010. Effect of soil texture and $\mathrm{pH}$ value on soil arthropod abundance. J. Centr. Sou. Univ. For. Tech., 30: 150-154.

Lövei, G.L. and Sunderland, K.D., 1996. Ecology and behavior of ground beetles (Coleoptera: Carabidae). Annu. Rev. Ent., 41: 231-256. https://doi.org/10.1146/ annurev.en.41.010196.001311

Lyons, A., Ashton, P.A., Powell, I. and Oxbrough, A., 2017. Impacts of contrasting conservation grazing management on plants and carabid beetles in upland calcareous grasslands. Agric. Ecosyst. Environ., 244: 22-31. https://doi.org/10.1016/j.agee.2017.04.020

Ma, K.J.B.S., 1994. Measurement of biotic community diversity I: measurement of $\alpha$-diversity (Part 1). Biodiv. Sci., 2: 162-168. https://doi.org/10.17520/ biods. 1994027

Majumdar, D.K., 2001. Irrigation water management: principles and practice. Prentice Hall of India Learning Private Limited, Delhi.

Magura, T., Tóthmérész, B. and Elek, Z., 2003. Diversity and composition of carabids during a forestry cycle. Biol. Conserv., 12: 73-85. https://doi. org/10.1023/A:1021289509500

Mace G,M., Norris, K. and Fitter A.H., 2012. Biodiversity and ecosystem services: a multilayered relationship. Trends Ecol. Evol., 27: 19-26. https:// doi.org/10.1016/j.tree.2011.08.006

Qu, L., Chen, J., Dong, G. and Shao, C., 2018. Heavy mowing enhances the effects of heat waves on grassland carbon and water fluxes. Sci. Total Environ., 627: 561-570.

Rook, A.J., Dumont, B., Isselstein, J., Osoro, K., WallisDeVries, M.F., Parente, G. and Mills, J., 2004. Matching type of livestock to desired biodiversity outcomes in pastures-a review. Biol. Conserv., 119: 137-150.

Scherber, C., Eisenhauer, N., Weisser, W.W., Schmid, W., Voigt, M., Fischer, E., Schulze, C., Roscher, A., Weigelt, E., Allan, H., Bessler, M., Bonkowski, N., Buchmann, F., Buscot, L.W., Clement, A., Ebeling, C., Engels, S., Halle, I., Kertscher, A., Klein, R., Koller, E., Kowalski, V., Kummer, A., Kuu, M., Lange, D., Lauterbach, C., Middelhoff, V., Migunova, A., Sabais, S., Scheu, J., Schumacher, V.M., Temperton, T. and Tscharntke, W., 2010. Bottom-up effects of plant diversity on multitrophic interactions in a biodiversity experiment. Nature, 468: 553. https://doi.org/10.1038/nature09492

Schirmel, J., Mantilla-Contreras, J., Gauger, D. and Blindow, I., 2015. Carabid beetles as indicators for shrub encroachment in dry grasslands. Ecol. Indic., 49: 76-82. https://doi.org/10.1016/j. ecolind.2014.09.041

Scimone, M., Rook, A.J., Garel, J.P. and Sahin, N., 2007. Effects of livestock breed and grazing intensity on grazing systems: 3. Effects on diversity of vegetation. Grass Forage Sci., 62: 172-184. https:// doi.org/10.1111/j.1365-2494.2007.00579.x

Song, S., Pang, H., Wang, Z. and Wang, X., 2017. Community structure and diversity of orthopteran in Mt.Yunwu Grassland Nature Reserve, Ningxia. $J$. Ningxia Univ., 38: 180-185.

Spellerberg, I.F. and Fedor, P.J., 2003. A tribute to Claude Shannon (1916-2001) and a plea for more rigorous use of species richness, species diversity and the 'Shannon-Wiener'Index. Global Ecol. Biogeogr., 12: $177-179 . \quad$ https://doi.org/10.1046/j.1466822X.2003.00015.X

Symondson, W., Cesarini, S., Dodd, P., Harper, G., Bruford, M., Glen, D., Wiltshire, C. and Harwood, J., 2006. Biodiversity vs. biocontrol: positive and negative effects of alternative prey on control of slugs by carabid beetles. B. Entomol. Res., 96: 637645. https://doi.org/10.1017/BER2006467

Tälle, M., Fogelfors, H., Westerberg, L. and Milberg, P., 2015. The conservation benefit of mowing vs grazing for management of species-rich grasslands: a multi-site, multi-year field experiment. Nord. J. Bot., 33: 761-768. https://doi.org/10.1111/njb.00966

Tälle, M., Deák, B., Poschlod, P., Valkó, O., Westerberg, L. and Milberg, P., 2016. Grazing vs. mowing: A 
meta-analysis of biodiversity benefits for grassland management. Agric. Ecosyst. Environ., 222: 200212. https://doi.org/10.1016/j.agee.2016.02.008

Tsafack, N., Rebaudo, F., Wang, H., Nagy, D.D., Xie, Y., Wang, X. and Fattorini, S., 2019. Carabid community structure in northern China grassland ecosystems: Effects of local habitat on species richness, species composition and functional diversity. Peer J., 6: e6197. https://doi.org/10.7717/peerj.6197

Vittum, P.J. and Tashiro, H., 1980. Effect of Soil pH on Survival of Japanese Beetle and European Chafer Larvae. J. econ. Ent., 73: 577-579.

Wang, J., Lü, Z., Yin, C., Li, J. and Wu, W., 2017. The shelter belt effect: beetles in the litter-layer of Tamarix nebkha in the north rim of Taklamakan. Acta Ecol. Sin., 37: 6504-6510.

Wang, Z.X., Zhang, Y.H., Wang, X.P., 2015. Diversity and community structure of beetles in Yunwu
Mountain grassland, Ning Xia. Pratacult. Sci., 32: 1156-1163.

Xie, Y. and Wittig, R., 2004. The impact of grazing intensity on soil characteristics of Stipa grandis and Stipa bungeana steppe in northern China (autonomous region of Ningxia). Acta Oecol., 25: 197-204. https:// doi.org/10.1016/j.actao.2004.01.004

Yan, Y.C., Tang, H.P. and Xin, X.P.J.A.E.S., 2009. Advances in research on the effects of exclosure on grasslands. Acta Ecol. Sin., 29: 5039-5046.

Zhang, Y.H., Wang, Z.X., Chang, C.Y., Wang, X.P., S.O., 2016. Community structure and diversity of moth in Yunwu Mountain National Nature Reserve. Acta Agrect. Sin., 24: 647-651.

Zhao, X.Y., Li, H.H., Cheng, J.M., Su, J.S. and Zhu, R.B., 2014. Value assessment of typical steep ecosystem in Yunwu mountain national nature reserve. Acta Agrect. Sin., 22: 217-223. 